Check for updates

Cite this: RSC Adv., 2021, 11, 5729

Received 24th October 2020 Accepted 15th January 2021

DOI: $10.1039 /$ dOra09079d

rsc.li/rsc-advances

\section{Research development on graphitic carbon nitride and enhanced catalytic activity on ammonium perchlorate}

\begin{abstract}
Danna Ma, iD Xiaomeng Li, ${ }^{*}$ Xiaoqing Wang and Yunjun Luo (D)
Recently, graphitic carbon nitride $\left(\mathrm{g}-\mathrm{C}_{3} \mathrm{~N}_{4}\right)$ has attracted considerable attention due to its attractive features including excellent electrochemical performance, suitable band gap, nontoxicity, and high mechanical and thermal stability. Such unique advantages endow it with promising applications in batteries, photocatalysts, photodegradation, and so on. In particular, it has been applied to catalyze the thermal decomposition of ammonium perchlorate (AP) and has shown excellent performance. In this review, the structure, preparation methods and exfoliation strategies of $\mathrm{g}-\mathrm{C}_{3} \mathrm{~N}_{4}$ are comprehensively introduced. Furthermore, the enhanced catalytic mechanism for the thermal decomposition of AP is discussed in detail, and a future research direction is also proposed.
\end{abstract}

\section{Introduction}

In the past decades, the research upsurge of "metal-free catalysis" has rapidly set off in domestic and foreign research fields. ${ }^{1-5}$ Graphitic carbon nitride $\left(\mathrm{g}-\mathrm{C}_{3} \mathrm{~N}_{4}\right)$, as one of the oldest polymer derivatives, has attracted broad attention for a long time due to its earth-abundance, good chemical inertness and biocompatibility. ${ }^{6-10}$ As an ancient and new metal-free catalyst, carbon nitride can be traced back to the foundation of catalytic chemistry and organic chemistry, as one of the oldest artificial polymers ever synthesized. They were firstly prepared by Berzelius in 1830, and a few years later, due to their yellowish color, were named "melon" by Liebig (Fig. 1). ${ }^{11}$ However, the molecular structure of early carbon nitride compounds has always puzzled researchers due to the coexistence of multiple phases in the synthesis process. It was not until the 1980s that the structure was clearly illustrated via theoretical calculations. In 1922, Frankili formally came up with the concept of carbon nitride. ${ }^{12}$ In 1996, Teter and Yamaki employed the firstprinciples pseudopotential method to calculate the structure of carbon nitride with different diameters. ${ }^{13}$ There are currently five different crystal structures of $\mathrm{C}_{3} \mathrm{~N}_{4}$ : $\quad-\mathrm{C}_{3} \mathrm{~N}_{4}, \quad-\mathrm{C}_{3} \mathrm{~N}_{4}$, cubic phase $\mathrm{C}_{3} \mathrm{~N}_{4}$, pseudocubic phase $\mathrm{C}_{3} \mathrm{~N}_{4}$ and graphitic phase $\mathrm{C}_{3} \mathrm{~N}_{4}$. Further research confirmed that $\mathrm{g}-\mathrm{C}_{3} \mathrm{~N}_{4}$ is energetically favored and is the most stable structure in the carbon nitride family.

Since Wang and co-workers published an article in the Nature materials in 2009 and showed that $\mathrm{g}-\mathrm{C}_{3} \mathrm{~N}_{4}$ could be used as a promising photocatalyst, ${ }^{\mathbf{1 4}}$ arduous efforts have been made for the preparation of $\mathrm{g}-\mathrm{C}_{3} \mathrm{~N}_{4}$. However, the selection of synthetic strategies, precursors and conditions are always

School of Materials Science and Engineering, Beijing Institute of Technology, Beijing, 100081, China. E-mail: 13651278705@139.com ignored. So far, electrodeposition technology, ${ }^{15}$ solvothermal, ${ }^{\mathbf{1 6}, 17}$ solid state reaction ${ }^{18}$ and thermal decomposition $^{19-24}$ have been used to prepare $\mathrm{g}-\mathrm{C}_{3} \mathrm{~N}_{4}$, among which thermal decomposition is the most widely. Actually, different composition strategies have their advantages and drawbacks, which need to be carefully evaluated based on the actual needs of the product. In addition, various precursors are used to synthesize $\mathrm{g}-\mathrm{C}_{3} \mathrm{~N}_{4}$, and the properties of the obtained products are quite different.

Motivated by its graphite layered structure with weak van der Waals force between layers, it is quite prospective to delaminating bulk g- $\mathrm{C}_{3} \mathrm{~N}_{4}$ into a few layers or monolayers. ${ }^{25-31}$ Such nanosheets not only retain the original properties of the bulk $\mathrm{g}$ $\mathrm{C}_{3} \mathrm{~N}_{4}$, but also have a larger specific surface area, which<smiles>Nc1nc(N)nc(N)n1</smiles><smiles>Nc1nc(N)nc(Nc2nc(N)nc(N)n2)n1</smiles><smiles>NC1=NC2=NC(N)=NC3=NC(N)=NC(=N1)N23</smiles>

(d)<smiles>CC1=NC2=NC(C)=NC3=NC(N)=NC(=N1)N23</smiles>

Fig. 1 Carbon and nitrogen containing materials: (a) melamine, (b) melam, (c) melem, (d) melon obtained from the thermolysis of mercury(॥) thiocyanate as presented by Liebig. ${ }^{11}$ 
increases the number of catalytic sites. Hence, a large amount of efforts have been put into the preparation of nanosheets, which could immensely widen the applications of the products. Although the strategies of exfoliating nanosheets have developed rapidly, the efficiency (both time and material) and environmental friendliness still need to be significantly improved.

Plentiful remarkable reviews are available that place emphasis on the applications in the photocatalytic field. Nevertheless, only a small fraction of studies have underlined g$\mathrm{C}_{3} \mathrm{~N}_{4}$ as a catalyst for the thermal decomposition of AP. ${ }^{32-37}$ Studies have shown that $\mathrm{g}-\mathrm{C}_{3} \mathrm{~N}_{4}$ could not only reduce the decomposition temperature of $\mathrm{AP}$, but also increase the heat released by decomposition. This review is focused on the up-todate developments in the preparation, exfoliation, and also the novel application in catalysis of AP decomposition and discusses current challenges and key issues that need to be addressed in future research.

\section{Preparation and structure of $\mathrm{g}$ - $\mathrm{C}_{3} \mathrm{~N}_{4}$}

There are two possible structures of $\mathrm{g}-\mathrm{C}_{3} \mathrm{~N}_{4}$, which take $s$ triazine ring $\left(\mathrm{C}_{3} \mathrm{~N}_{3}\right)$ and tri-s-triazine ring $\left(\mathrm{C}_{6} \mathrm{~N}_{7}\right)$ as the basic structural units to form an infinite network structure (Fig. 2a and b). ${ }^{38}$ Density Functional Theory (DFT) simulation results show that $\mathrm{g}-\mathrm{C}_{3} \mathrm{~N}_{4}$ based on tri-s-triazine ring is much more favorable in terms of energy under ordinary ambient conditions. ${ }^{39}$ In order to obtain the possibility of the tri-s-triazine structure, Kroke performed total energy calculations of various structures using density functional theory. They reproduced all the relative energies of diamond-like and $\mathrm{g}-\mathrm{C}_{3} \mathrm{~N}_{4}$ structures previously suggested, and found that a tri-s-triazine based layered structure $\mathrm{g}-\mathrm{C}_{3} \mathrm{~N}_{4}$ is energetically more favorable, by $30 \mathrm{~kJ} \mathrm{~mol}^{-1}$ in comparison to triazine based $\mathrm{g}-\mathrm{C}_{3} \mathrm{~N}_{4}$, and thus should exist. Zhu et al. used DFT calculations to calculate the theoretical bond lengths in the $\mathrm{g}-\mathrm{C}_{3} \mathrm{~N}_{4}$. There are three nonequivalent $\mathrm{N}$ atoms and two non-equivalent $\mathrm{C}$ atoms labeled as $\mathrm{N} 1, \mathrm{~N} 2, \mathrm{~N} 3, \mathrm{C} 1$ and $\mathrm{C} 2$, respectively (Fig. 3). And the bond lengths of N1-C1, C1-N2, N2-C2 and C2-N3 are $1.39 \AA, 1.33 \AA$, $1.34 \AA$ and $1.47 \AA$, separately. ${ }^{40}$ DFT calculations was performed by David M. et al. to simulate the optimized structure of $\mathrm{g}-\mathrm{C}_{3} \mathrm{~N}_{4}$. And the $\mathrm{C}-\mathrm{N}$ bond lengths were depicted in Fig. 4. The calculated bond lengths of $\mathrm{C}-\mathrm{N}$ were $1.33 \AA$, $1.39 \AA$, and $1.48 \AA{ }^{41}$ Brito
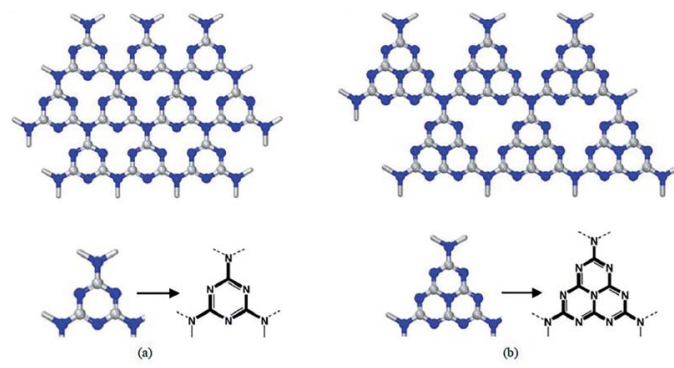

Fig. 2 The two structures proposed of $\mathrm{g}-\mathrm{C}_{3} \mathrm{~N}_{4}$ (a) $\mathrm{g}_{1}-\mathrm{C}_{3} \mathrm{~N}_{4}$ based on $\mathrm{s}$ triazine and (b) $\mathrm{g}_{2}-\mathrm{C}_{3} \mathrm{~N}_{4}$ based on tri-s-triazine. ${ }^{38}$

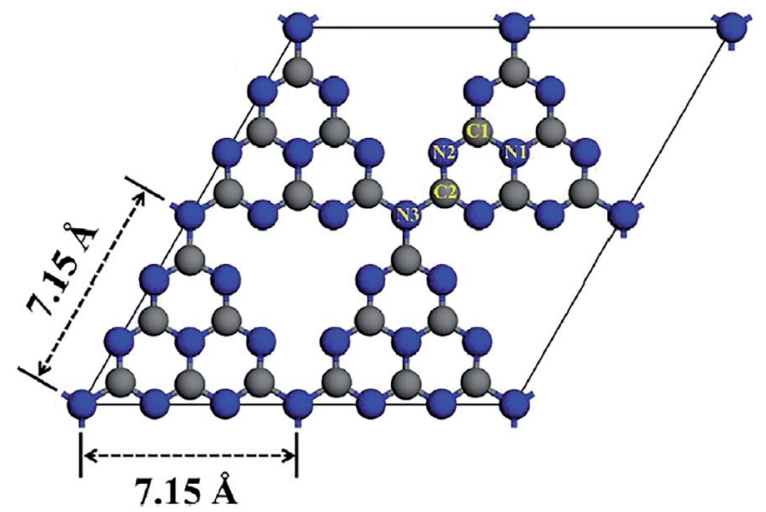

Fig. 3 Optimized structure of monolayer $\mathrm{g}-\mathrm{C}_{3} \mathrm{~N}_{4}$. The blue and gray balls represent $\mathrm{N}$ and $\mathrm{C}$ atoms, respectively. ${ }^{40}$

has performed Monte Carlo and ab initio calculations to propose and investigate the morphology, relative energetic stability, and electronic properties of $\mathrm{g}-\mathrm{C}_{3} \mathrm{~N}_{4}$ structures. Their results indicate that the increase of concentration of nitrogen leads to the coalescence of vacancies and therefore the increase in the size of nanopores. The smallest nanopore in their structures is based on a single vacancy surrounded by three pyridinic nitrogens. This type of nanopore is observed in the g$\mathrm{C}_{3} \mathrm{~N}_{4}$ structure based on condensed $s$-triazines. Therefore, the pores of the tri-s-triazine structure of $g-\mathrm{C}_{3} \mathrm{~N}_{4}$ are larger than that of triazine based $\mathrm{g}-\mathrm{C}_{3} \mathrm{~N}_{4} \cdot{ }^{42}$ As an emergent material, g- $\mathrm{C}_{3} \mathrm{~N}_{4}$ possesses a two-dimensional layered structure similar to graphite. The atoms in the layers are arranged in a honeycomb pattern with strong covalent bonds and the layers are connected by weak van der Waals force. The basic structural unit of g- $\mathrm{C}_{3} \mathrm{~N}_{4}$ is the tri-s-triazine ring, which is connected by terminal $\mathrm{N}$ atoms to form an infinitely extending plane. ${ }^{\mathbf{4 3 , 4 4}}$ Generally, it is a challenge to obtain a perfect crystalline two-dimensional layered structure. Incomplete polycondensed triazine ring structure will

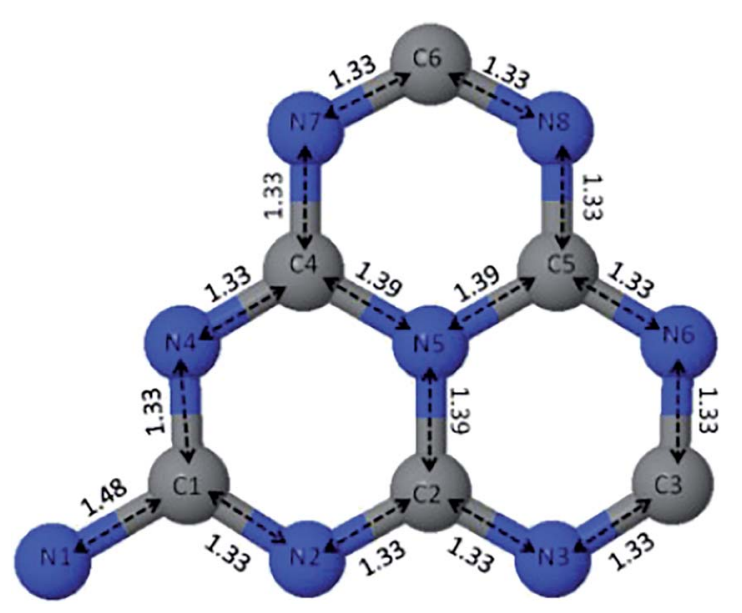

Fig. 4 Unit cell of the tri-s-triazine-based structure of $\mathrm{g}-\mathrm{C}_{3} \mathrm{~N}_{4}$ after optimization. $\mathrm{C}-\mathrm{N}$ bond lengths are expressed in $\AA$. Blue spheres represent the nitrogen atoms and grey spheres represent carbon atoms; each atom is labeled accordingly. ${ }^{41}$ 
result in a large number of $-\mathrm{NH}_{2}$ and $-\mathrm{NH}$ - groups at the edge of rings. Usually, $\mathrm{g}-\mathrm{C}_{3} \mathrm{~N}_{4}$ are mixtures of samples with different degrees of polymerization, and therefore the analysis and description of its specific structure are still very difficult.

Up to date, the pristine $\mathrm{g}-\mathrm{C}_{3} \mathrm{~N}_{4}$ has not been found in nature. Therefore, the current research and application of $\mathrm{g}-\mathrm{C}_{3} \mathrm{~N}_{4}$ are completely dependent on experimental synthesis. Various methods were tried to prepare $\mathrm{g}-\mathrm{C}_{3} \mathrm{~N}_{4}$ previously, such as electrochemical deposition, solvothermal, solid state reaction and thermal decomposition. In this paper, the effect of synthesis strategies, condition parameters and precursors on the performance of $\mathrm{g}-\mathrm{C}_{3} \mathrm{~N}_{4}$ will be illustrated in detail.

Usually, for solvothermal, carbon-nitrogen organic small molecules such as melamine or melamine chloride as precursors react in a high-boiling organic solvent used as heatconducting medium at certain temperatures. Bai et al. prepared deformable hollow g- $\mathrm{C}_{3} \mathrm{~N}_{4}$ nanospheres (Fig. $5 \mathrm{a}-\mathrm{d}$ ) by the solvothermal method with silica spheres as template. ${ }^{16}$ The unique hollow nanospheres deformed easily other than breaking under external pressure. $\mathrm{Hu}$ et al. also successfully fabricated g- $\mathrm{C}_{3} \mathrm{~N}_{4}$ using acetonitrile as a solvent by solvothermal method. ${ }^{17}$ By increasing the solvothermal temperature and the filling fraction of the autoclave, the mixed pseudocubic/beta phase could be converted into a graphitic phase. The morphology of the product prepared by this method is uniform and controllable, so it can be used to prepare $\mathrm{g}-\mathrm{C}_{3} \mathrm{~N}_{4}$ with particular morphology. However, this approach is limited by many conditions. In addition to temperature, the viscosity, density and polarity of the solvent also play crucial roles in the properties of the product. What's more, the organic solvent used in the preparation process of this method has serious problems of environmental pollution, and the yield $(<5 \%)$ is limited by the solubility of the raw materials.

The solid-state reaction does not involve solvent but react directly, with high selectivity, high yield, simple process and so

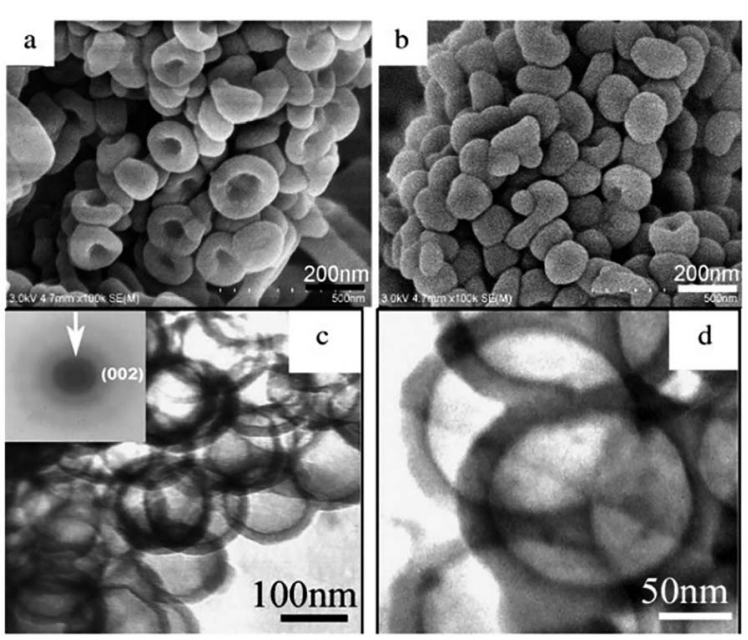

Fig. 5 FE-SEM images of the product (deformable hollow g- $\mathrm{C}_{3} \mathrm{~N}_{4}$ nanospheres): (a) the images of the pie shape; (b) extruded hollow spheres; (c) the TEM and SAED images of the sample; (d) another magnification TEM image. ${ }^{16}$

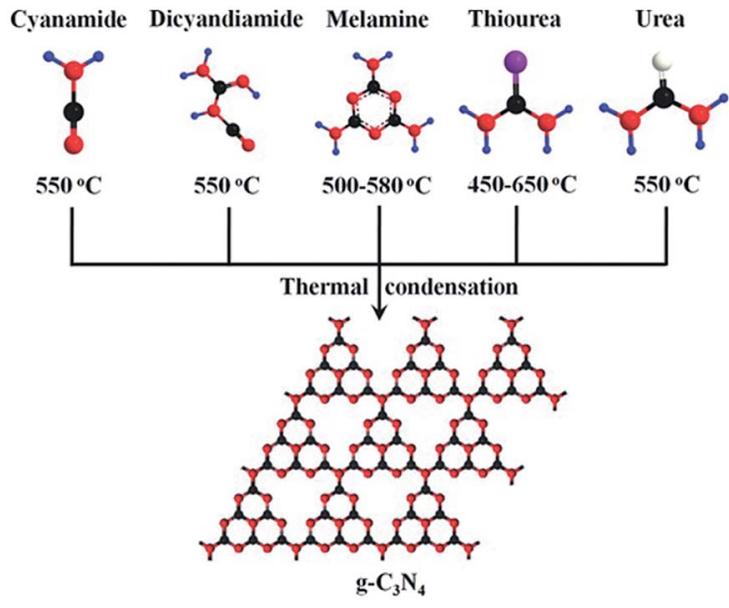

Fig. 6 Schematic illustration of the main routes of the synthesis of $\mathrm{g}$ $\mathrm{C}_{3} \mathrm{~N}_{4}$ by different precursors. ${ }^{46}$

on. Zhang et al. chose melamine to react with melamine chloride and successfully produce carbon nitride with high crystallinity. ${ }^{18}$ Unfortunately, the product contains a small amount of heteroatomic chlorine. Only when under the condition of high temperature and pressure, the solid-state reaction can show an efficient reaction rate. In addition, the materials are often mixed in a powder state, which may result in an insufficient contact between the reactants during the reaction.

Electrodeposition technology requires a specific precursor solution as the electrolyte, which reacts under the action of direct current, and a thin film of $\mathrm{g}-\mathrm{C}_{3} \mathrm{~N}_{4}$ is grown on the electrode substrate. In Zhang's study, $\mathrm{g}^{-} \mathrm{C}_{3} \mathrm{~N}_{4}$ thin films were deposited at room temperature on $\mathrm{Si}$ substrates by electrodeposition in saturated acetonitrile solution of cyanuric chloride

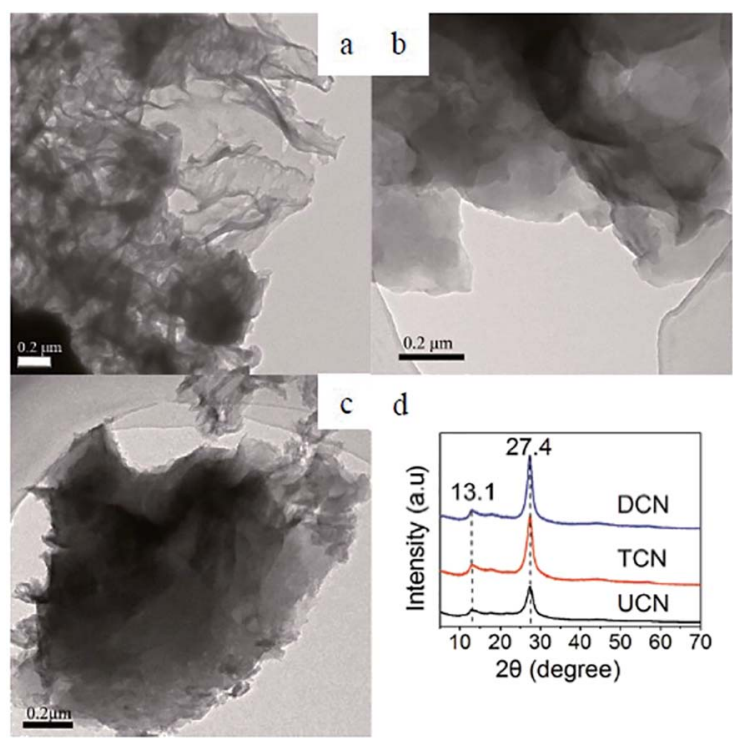

Fig. 7 Typical TEM images of $\mathrm{g}-\mathrm{C}_{3} \mathrm{~N}_{4}$. (a) UCN, (b) TCN, (c) DCN. (d) Experimental XRD patterns of the polymeric carbon nitride, which reveal a graphitic structure with an inter-planar stacking distance of aromatic units of $0.326 \mathrm{~nm} .{ }^{48}$ 
Table 1 Microstructure of $\mathrm{g}-\mathrm{C}_{3} \mathrm{~N}_{4}$ synthesized from different precursors ${ }^{48}$

\begin{tabular}{|c|c|c|c|c|c|c|c|}
\hline & $\begin{array}{l}\mathrm{SA}^{a} \\
{\left[\mathrm{~m}^{2} \mathrm{~g}^{-1}\right]}\end{array}$ & $\begin{array}{l}\mathrm{PV}^{b} \\
{\left[\mathrm{~m}^{3} \mathrm{~g}^{-1}\right]}\end{array}$ & $\begin{array}{l}\mathrm{PD}^{c} \\
{[\mathrm{~nm}]}\end{array}$ & $\begin{array}{l}\mathrm{C} / \mathrm{N} \text { molar } \\
\text { ration }^{d}\end{array}$ & $\begin{array}{l}\mathrm{H}_{2} \text { evolution rate } \mathrm{r}^{e} \\
{\left[\mu \mathrm{mol} \mathrm{h}{ }^{-1}\right]}\end{array}$ & $\begin{array}{l}\mathrm{H}_{2} \text { evolution rate } \\
{\left[\mu \mathrm{mol} \mathrm{h}^{-1}\right]}\end{array}$ & $\begin{array}{l}\text { Band gap } \\
{[\mathrm{eV}]}\end{array}$ \\
\hline UCN & 69.6 & 0.321 & 18.2 & 0.72 & 0.25 & 47.2 & 2.73 \\
\hline TCN & 11.3 & 0.085 & 26.2 & 0.78 & 0.066 & 15.1 & 2.60 \\
\hline DCN & 12.3 & 0.086 & 24.4 & 0.79 & 0.083 & 20.9 & 2.66 \\
\hline
\end{tabular}

${ }^{a}$ BET surface area. ${ }^{b}$ Pore volume: BJH desorption cumulative volume of pores. ${ }^{c}$ Pore diameter: average pore diameter determined by BJH method. ${ }^{d}$ Element analysis from XPS survey. ${ }^{e}$ Hydrogen production from pure water. ${ }^{f}$ Hydrogen production from solution with TEA as sacrificial donor.

and melamine. ${ }^{15}$ The crystal structure of $\mathrm{g}-\mathrm{C}_{3} \mathrm{~N}_{4}$ is different from that of the amorphous sample after thermal polycondensation. This technology is not only easy to control, but also can effectively reduce the $\mathrm{C}-\mathrm{N}$ bonding reaction energy barrier and lower the temperature of the reaction. Recently, it has been applied to the preparation of $\mathrm{g}-\mathrm{C}_{3} \mathrm{~N}_{4}$ thin films.

Chemical Vapor Deposition (CVD) technology is mainly used to prepare thin film materials. By introducing highly reactive nitrogen, carbon atoms or ions into the reaction system, carbon nitride films are deposited on the substrate. Zhao et al. successfully fabricated $\mathrm{g}-\mathrm{C}_{3} \mathrm{~N}_{4}$ with mesoporous structure by facile vapor deposition method with nanometer silica as a template. ${ }^{45}$ This research provided a simple method for controlling the typical structure of $\mathrm{g}-\mathrm{C}_{3} \mathrm{~N}_{4}$ and improving its photocatalytic performance.

Generally, thermal polycondensation is the most commonly used technique to prepare $\mathrm{g}-\mathrm{C}_{3} \mathrm{~N}_{4}$. In this method, the precursor is polycondensed to form carbon nitride through thermal induction. Recently, high temperature polycondensation organic precursor method has been widely used due to its simple operation and suitable for large-scale production. ${ }^{\mathbf{1 9}}$ Scientific studies have shown that most cyanamides could be used as precursors to synthesize carbon nitride. As observed in Fig. 6, it is clear that $\mathrm{g}-\mathrm{C}_{3} \mathrm{~N}_{4}$ could be simply prepared from several N-rich precursors such as cyanamide, dicyandiamide, melamine, thiourea and urea. ${ }^{46}$ Yan et al. synthesized $g-\mathrm{C}_{3} \mathrm{~N}_{4}$ by directly heating low-cost melamine. ${ }^{47}$ Zhang et al. used urea to replace melamine as a precursor to prepare g- $\mathrm{C}_{3} \mathrm{~N}_{4} \cdot{ }^{48}$ Although carbon nitride can be obtained from different kinds of precursors, the physical and chemical properties of its products are not the same. Taking this into consideration, Zhang and his coworkers compared the properties of $\mathrm{g}-\mathrm{C}_{3} \mathrm{~N}_{4}$ prepared from three different precursors. For instance, the product obtained from urea contains a porous fold structure with a large specific



Fig. 8 Schematic of microwave procedure. ${ }^{49}$ surface area, while melamine-derived $\mathrm{g}-\mathrm{C}_{3} \mathrm{~N}_{4}$ presented a multilayered structure with a small specific surface area. As exhibited in the schematic illustration of Table 1 , compared with the other two precursors, the urea-derived $\mathrm{g}-\mathrm{C}_{3} \mathrm{~N}_{4}$ has a larger specific surface area and pore volume.

It is interesting to analyze the structure of these three samples. The TEM image in Fig. 7a shows a two-dimensional structure composed of small sheets with folds and irregular shapes. Meanwhile, large plate-like non-porous structures were found in TCN and DCN samples (Fig. 7b and c). Additionally, the XRD pattern of Fig. 7d shows a weaker peak intensity of UCN than that of TCN and DCN, suggesting that the crystallization of urea-derived $\mathrm{g}-\mathrm{C}_{3} \mathrm{~N}_{4}$ will be affected by urea. This further proves that products made from urea are fluffy and porous. Consequently, urea can be used as a precursor to fabricate a product with pores, which possesses a large specific surface area.

Apart from the methods mentioned above, Yuan et al. reported a rapid synthetic strategy (within several minutes) to prepare crystalline $\mathrm{g}-\mathrm{C}_{3} \mathrm{~N}_{4} \cdot{ }^{49}$ In their research, microwave was introduced into the system for synthesizing $\mathrm{g}-\mathrm{C}_{3} \mathrm{~N}_{4}$. As shown in Fig. 8, CuO is employed as the microwave absorbing material, which converts microwave energy into thermal energy, and raise the temperature to $1285 \mathrm{~K}$ in a short time (less than $7 \mathrm{~min}$ ). The morphology of the products obtained by this method is velvetlike sheets, and the specific surface area $\left(77 \mathrm{~m}^{2} \mathrm{~g}^{-1}\right)$ is slightly



Fig. 9 Fabrication strategies of $\mathrm{g}-\mathrm{C}_{3} \mathrm{~N}_{4}$ and $\mathrm{N}$-rich precursors. ${ }^{50}$ 
larger than those from bulk thermal treatment $\left(65.9 \mathrm{~m}^{2} \mathrm{~g}^{-1}\right)$. This innovative technology supplied an efficient and short duration route to prepare $\mathrm{g}-\mathrm{C}_{3} \mathrm{~N}_{4}$.

In addition to the traditional synthesis methods, people began to explore more novel methods for the synthesis of $\mathrm{g}-\mathrm{C}_{3} \mathrm{~N}_{4}$. In Fig. 9, apart from the methods mentioned above, molecular self-assembly, ionothermal synthesis and ionic liquid strategy were also included. ${ }^{50}$ Ionothermal synthesis is a method to synthesize the target product in a low volatile ion reaction environment with ionic liquid as the reaction medium. As a method of liquid phase method, ionothermal method could be regarded as an improvement of hydrothermal/solvothermal synthesis by changing the type of solvent. Compared with traditional solvents, it has the superiority of low vapor pressure, good stability, and high ionic conductivity. Gao et al. used a eutectic salt $\mathrm{LiCl} \cdot \mathrm{H}_{2} \mathrm{O}-$ $\mathrm{KCl}-\mathrm{NaCl}\left(1: 1: 1\right.$ weight ratio) with a low melting point $\left(355^{\circ} \mathrm{C}\right)$ as a solvent and mixed it with melamine in a ratio of $15: 1 .^{51} \mathrm{It}$ improves the transport of photogenerated electrons and holes, and reduces the electron-hole recombination rate.

\section{Exfoliation of $\mathrm{g}-\mathrm{C}_{3} \mathrm{~N}_{4}$}

g- $\mathrm{C}_{3} \mathrm{~N}_{4}$, as an attractive earth-abundant material, has a serious of merits such as metal-free, high stability, good biocompatibility, eco-friendly and nontoxicity. However, bulk g- $\mathrm{C}_{3} \mathrm{~N}_{4}$ suffers from low specific surface area $\left(<10 \mathrm{~m}^{2} \mathrm{~g}^{-1}\right)$ and rapid recombination of photo-generated electron-hole pairs which result in inferior catalytic effect, which greatly limit its application. Hitherto, plentiful efforts have been undertaken to prepare more efficient $\mathrm{g}-\mathrm{C}_{3} \mathrm{~N}_{4}$. There are numerous strategies to modify bulk g- $\mathrm{C}_{3} \mathrm{~N}_{4}$. Up to now, two-dimensional graphitic carbon nitride nanosheets (CNNS) have become a hot topic due to their high specific surface area of $200-300 \mathrm{~m}^{2} \mathrm{~g}^{-1}$, fast photogenic carrier migration rate, and abundant active sites. Compared with bulk materials, graphitic carbon nitride nanosheet possess greater advantages in the fields of energy storage, sensors, electronics and catalysis. ${ }^{52}$

Therefore, more and more scientists are focusing on the preparation of ultra-thin, high specific surface (theoretical up to $2500 \mathrm{~m}^{2} \mathrm{~g}^{-1}$ ), and strong catalytic activity of carbon nitride nanosheets. Generally speaking, two-dimensional materials can be obtained by peeling the corresponding layered materials, which not only has the intrinsic properties of layered materials, but also produces many new physical and chemical properties.

Analogous to the development of two-dimensional graphene from the layered graphite, the bulk $\mathrm{g}-\mathrm{C}_{3} \mathrm{~N}_{4}$ can be delaminated into single or a few layers of nanosheets due to the weak van der Waals force between the layers. Hitherto, several distinct strategies have been developed for the fabrication of two-dimensional g- $\mathrm{C}_{3} \mathrm{~N}_{4}$ nanosheets (CNNs). Such as thermal oxidation etching, ultrasonication-assisted liquid exfoliation and chemical exfoliation.

\subsection{Thermal oxidation etching}

For the first time, Niu et al. successfully obtained $\mathrm{g}-\mathrm{C}_{3} \mathrm{~N}_{4}$ nanosheets with a sickness of $2 \mathrm{~nm}$ by a simple top-down strategy, namely, thermal oxidation etching method. ${ }^{53}$ As shown in Fig. 10, the product has more pores and the volume significantly increased after thermal oxidation etching. It is noteworthy that the N-rich precursor in the crucible should be in full contact with air. Following the similar technique, Qian et al. successfully fabricated different thermal treated $\mathrm{g}-\mathrm{C}_{3} \mathrm{~N}_{4}$ samples with diverse duration ( $4 \mathrm{~h}, 5 \mathrm{~h}$ and $6 \mathrm{~h}) .{ }^{54}$ The holding time of heat treatment plays a vital role in the delamination of bulk $\mathrm{g}-\mathrm{C}_{3} \mathrm{~N}_{4}$. With the extension of heat treatment time, the morphology of bulk samples became fluffier. Furthermore, the specific surface area increased significantly. However, this method still has the following shortcomings: firstly, in the process of thermal oxidation, a large number of $\mathrm{NH}_{3}, \mathrm{CO}_{2}$ and other harmful gases will be generated. Secondly, the yield of the product is very low $(\sim 6 \%)$. Thirdly, the morphology and size of the nanosheets are greatly affected by the experimental temperature.

\subsection{Ultrasonication-assisted liquid exfoliation}

Ultrasonication-assisted liquid phase exfoliation is to gradually infiltrate the solvent molecules into the layers of materials with the help of ultrasound, expand the layer spacing, weaken the van der Waals forces between layers, so as to achieve the purpose of exfoliation. Different solvents have different exfoliation effects.

In Yang's work, isopropanol (IPA) was used as a solvent. ${ }^{55}$ After $10 \mathrm{~h}$ of ultrasound, the resulting $\mathrm{g}-\mathrm{C}_{3} \mathrm{~N}_{4}$ nanosheets possess high specific surface area $\left(384 \mathrm{~m}^{2} \mathrm{~g}^{-1}\right)$, and the thickness reduced to $2 \mathrm{~nm}$. Similar research has also been utilized by Wang et al. for an innovative atomic single layer $g-\mathrm{C}_{3} \mathrm{~N}_{4}$ with a thickness of $0.5 \mathrm{~nm} .{ }^{56}$ Briefly, they first fabricated bulk g- $\mathrm{C}_{3} \mathrm{~N}_{4}$ by thermal condensation, followed by thermal oxidation etching to prepare a few layers of nanosheets, and finally used isopropanol as a solvent to obtain a single-layer product by ultrasound. In addition, Zhao et al. reported a single layer of g$\mathrm{C}_{3} \mathrm{~N}_{4}$ with thickness of $0.4-0.5 \mathrm{~nm} .{ }^{57}$ Unlike Wang's method,

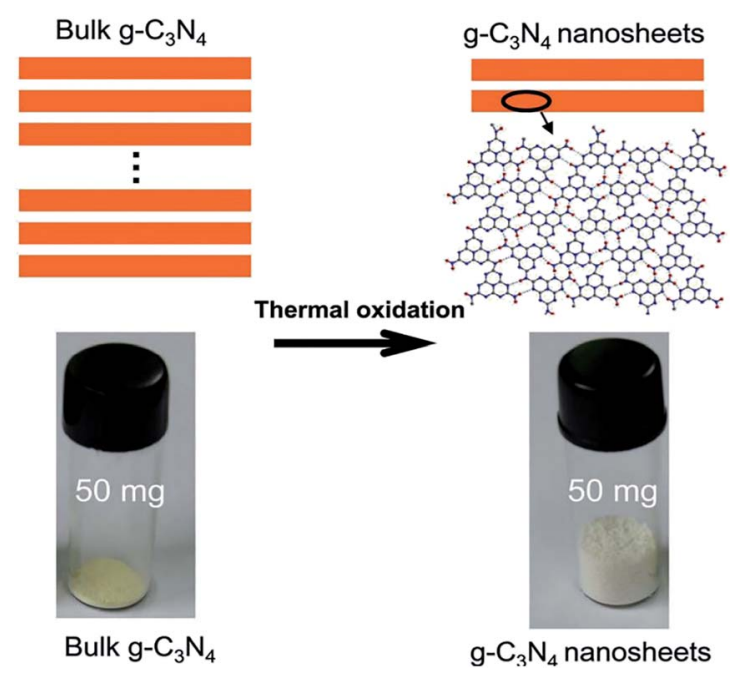

Fig. 10 Schematic of the structures of the bulk $\mathrm{g}-\mathrm{C}_{3} \mathrm{~N}_{4}$ and the g$\mathrm{C}_{3} \mathrm{~N}_{4}$ nanosheets. ${ }^{53}$ 
Zhao used methanol as the solvent and ultrasonic for $4 \mathrm{~h}$. Interestingly, they obtained the samples by a "bulk-nanosheetsingle layer" strategy. In another type of exfoliation way, Miao et al. prepared 2D nanosheets by two processes: they first treated the sample with acid and then stripped it in the liquid phase (Fig. 11). ${ }^{58}$ The initial acid treatment reduced the thickness of graphitic carbon nitride and shortened the time for subsequent ultrasound. Li et al. fabricated single layer g- $\mathrm{C}_{3} \mathrm{~N}_{4}$ nanosheets by directly delaminating its bulk counterpart materials. ${ }^{59}$ Unlike traditional organic solvents, they employed the alkaline potassium hydroxide $(\mathrm{KOH})$ as the solvent. After being treated with potassium hydroxide $(\mathrm{KOH})$, the interaction of $\mathrm{OH}$ - with terminal $-\mathrm{NH}_{2}$ or bridge $-\mathrm{NH}$ - group had accelerated the delamination of the lamellar structure. Importantly, the original crystal and chemical structure of $\mathrm{g}-\mathrm{C}_{3} \mathrm{~N}_{4}$ was well maintained.

Sparked by what was mentioned above, Li and coworkers investigated the effect of potassium hydroxide concentration on the properties of the nanosheet. ${ }^{60}$ As the amount of $\mathrm{KOH}$ increased from $0.1 \mathrm{M}$ to $1 \mathrm{M}$, the catalytic promoted. Nevertheless, excessive concentration caused structural damage. Owing to the merits mentioned above, based on alkalization treatment, Yu et al. introduced $\mathrm{K}^{+}$doping. ${ }^{61}$ Before treated with $\mathrm{KOH}$, they mixed the precursor melamine with potassium chloride evenly, which is the main factor to improve the performance. Potassium ion $\left(\mathrm{K}^{+}\right)$has certain intercalation, which urges it to enter the layered structure. It improves the electron transport capacity, breaks the edge structure of the alkalized materials, destroys the electron balance, and reduces the recombination rate of photogenic carriers and holes. However, overlarge concentration made the effect down. Considering the difficulty of removing organic solvents and environmental issues, Zhang et al. highlighted an available pathway to prepare g- $\mathrm{C}_{3} \mathrm{~N}_{4}$ nanosheets. ${ }^{62}$ Ultrathin g- $\mathrm{C}_{3} \mathrm{~N}_{4}$ nanosheets were prepared from bulk materials by green liquid exfoliation in water for the first time. In detail, melamine was heated directly at $600{ }^{\circ} \mathrm{C}$ for $2 \mathrm{~h}$ to get the yellow bulk g- $\mathrm{C}_{3} \mathrm{~N}_{4}$. Subsequently, the bulk powder was ultrasound for $16 \mathrm{~h}$. The asprepared samples showed a height of $2.5 \mathrm{~nm}$ approximately. Fascinatingly, the nanosheets obtained remained stable in both acid and alkaline. Furthermore, the brand-new materials manifested extraordinary performance, which induces their extremely high PL quantum yield up to $19.6 \%$. Zhang et al. recently reported an attractive result of $\mathrm{CdS} / \mathrm{g}-\mathrm{C}_{3} \mathrm{~N}_{4}$ nanosheets. ${ }^{63}$ Dimethyl sulfoxide (DMSO) could be utilized as a solvent. Besides, they introduced cadmium ions (Cd) into the solvent. As could be seen in Fig. 12, layered substances can be separated by the synergistic effect of ion insertion and the

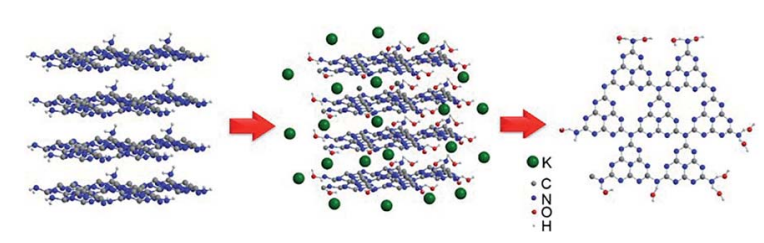

Fig. 11 Illustration of the exfoliation procedure. ${ }^{58}$ ultrasonic of the solvent. Compared with solvent exfoliation alone, the synergistic effect is more favorable to obtain ultrathin nanosheets, which was sonicated for $1 \mathrm{~h}$ and then was transferred into autoclave maintained for $12 \mathrm{~h}$.

In summary, the Ultrasonication-assisted liquid exfoliation is simple to operate and easy to control. Nevertheless, such technique still involves low exfoliation efficiency, lengthy duration (6-20 h) and uneven thickness. Most importantly, when a powder sample is required, the solvent needs to be removed and this strategy cannot be employed for large-scale production of industrial materials.

\subsection{Chemical exfoliation}

Although significant progress has been made in obtaining g$\mathrm{C}_{3} \mathrm{~N}_{4}$ nanosheets through ultrasonic solution exfoliation and thermal oxidation etching strategy, the issues of low efficiency still exist. Therefore, it is necessary to seek a novel method to prepare single layer or few layered $\mathrm{g}-\mathrm{C}_{3} \mathrm{~N}_{4}$ nanosheet materials whether from the scientific or practical perspectives. ${ }^{64}$ Chemical exfoliation is another widely used method for exfoliating layered compounds through redox chemical modification, insertion, and ion exchange. Compared with liquid phase exfoliation, chemical exfoliation could shorten the exfoliation time, and improve the efficiency, which has practical application value.

Very recently, Xu and coworkers successfully reported g- $\mathrm{C}_{3} \mathrm{~N}_{4}$ nanosheets with single atomic layer structure by a simple chemical exfoliation method. ${ }^{65}$ Motivated by graphene, they introduced concentrated sulfuric acid $\left(\mathrm{H}_{2} \mathrm{SO}_{4}\right)$. A single layer of g- $\mathrm{C}_{3} \mathrm{~N}_{4}$ nanosheet was obtained by intercalation of $\mathrm{g}-\mathrm{C}_{3} \mathrm{~N}_{4}$ with concentrated sulfuric acid $\left(\mathrm{H}_{2} \mathrm{SO}_{4}\right)$. On account of the sonication and the heat release when concentrated sulfuric acid dissolved in water, bulk $\mathrm{g}-\mathrm{C}_{3} \mathrm{~N}_{4}$ was exfoliated into single layered nanosheet. At the same time, the effect of different concentrations of sulfuric acid on the exfoliation effect was investigated, and the results showed that only concentrated sulfuric acid (98 wt $\%$ ) can obtain single layer $\mathrm{g}-\mathrm{C}_{3} \mathrm{~N}_{4}$ nanosheet. Compared with thermal oxidation etching and liquid exfoliation for the preparation of $\mathrm{g}-\mathrm{C}_{3} \mathrm{~N}_{4}$ nanosheets, the chemical exfoliation is more economical and endows the nanosheets thinner. Most recently, Tong and coworkers present their recent discovery that g- $\mathrm{C}_{3} \mathrm{~N}_{4}$ could be rapidly decomposed and stripped off by carefully dropping water into concentrated sulfuric acid. ${ }^{66} \mathrm{~A}$ feasible principle was illustrated in Fig. 13. Compared with individual concentrated sulfuric acid, the addition of water greatly

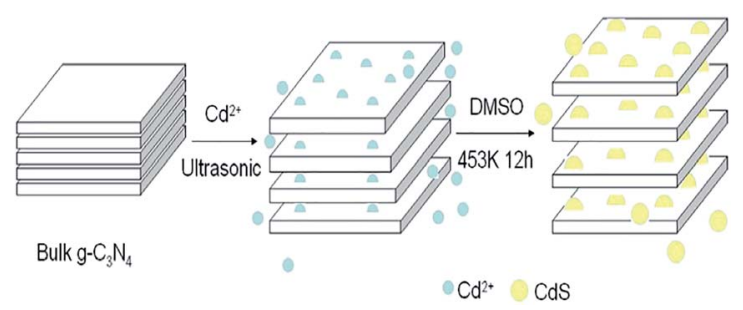

Fig. 12 Mechanism for the formation of the ultrasonic $\mathrm{CdS} / \mathrm{g}-\mathrm{C}_{3} \mathrm{~N}_{4}$ nanosheets. ${ }^{63}$ 
increases the heat release of concentrated sulfuric acid and the final yield up to $70 \%$. Furthermore, the reaction time was reduced significantly to less than $30 \mathrm{~min}$ and the as-prepared g$\mathrm{C}_{3} \mathrm{~N}_{4}$ nanosheets possess uniformly distributed size.

In addition to concentrated sulfuric acid, concentrated hydrochloric acid $(\mathrm{HCl})$ and nitric acid $\left(\mathrm{HNO}_{3}\right)$ can also be used to exfoliate the bulk $\mathrm{g}-\mathrm{C}_{3} \mathrm{~N}_{4}$. Protonation of bulk $\mathrm{g}-\mathrm{C}_{3} \mathrm{~N}_{4}$ with concentrated hydrochloric acid not only increases specific surface area but also improves its dispersion. Zhang et al. reported that bulk $\mathrm{g}-\mathrm{C}_{3} \mathrm{~N}_{4}$ could be reversibly protonated by strong acid without disorganizing its unique chemical structure. ${ }^{67}$ Herein, they mixed the bulk g- $\mathrm{C}_{3} \mathrm{~N}_{4}$ with hydrochloric acid $(\mathrm{HCl}, 37 \%)$, the BET surface area of as-prepared $\mathrm{g}-\mathrm{C}_{3} \mathrm{~N}_{4}-$ $\mathrm{H}^{+}-\mathrm{Cl}^{-}$increased from 8 to $30 \mathrm{~m}^{2} \mathrm{~g}^{-1}$. Intriguingly, the process is invertible and controllable. When heated at different temperatures $\left(350{ }^{\circ} \mathrm{C}, 450{ }^{\circ} \mathrm{C}, 550{ }^{\circ} \mathrm{C}\right), \mathrm{HCl}$ in the $\mathrm{g}-\mathrm{C}_{3} \mathrm{~N}_{4}-\mathrm{H}^{+}-$ $\mathrm{Cl}^{-}$could be removed. On this basis, the adjustable surface charge provides a method for the preparation of heterostructures with different charge objects in different $\mathrm{pH}$ systems through electrostatic self-assembly.

In summary, products prepared by thermal oxidation methods usually have a large specific surface area and the operation steps are relatively simple. However, the yield of nanosheets is low, which is not suitable for mass production. The ultrasonication-assisted liquid exfoliation is simple to operate and easy to control but is time-consuming, the organic solvent employed in the exfoliation process is usually more expensive or harmful to the environment and needs to be removed during subsequent use. While chemical exfoliation significantly improves the yield of nanosheets, shortens the exfoliation time, reduces costs, and is suitable for large-scale preparation of $\mathrm{g}-\mathrm{C}_{3} \mathrm{~N}_{4}$ nanosheets. Each of the above methods has its advantages and disadvantages. In practice, we should choose the appropriate method according to the actual requirements. At present, most methods cannot meet the requirements of controllable number of layers, homogeneous, and good crystallinity of ultra-thin nanosheets at the same time, and there is still a certain gap with large-scale production. Large-scale exfoliation method, and preparing highconcentration ultra-thin $\mathrm{g}-\mathrm{C}_{3} \mathrm{~N}_{4}$ nanosheets stable suspensions, is still the focus of future research.

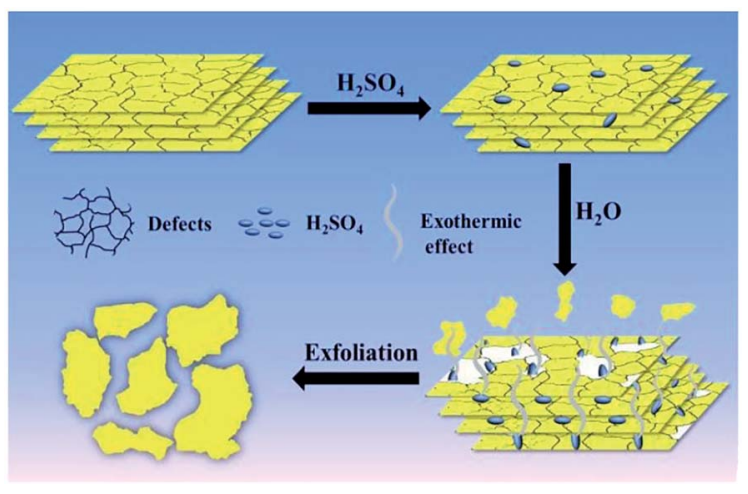

Fig. 13 Schematic illustration of the exfoliation process of $\mathrm{g}-\mathrm{C}_{3} \mathrm{~N}_{4}{ }^{66}$

\section{Application in thermal decomposition of AP}

As the most stable allotrope in the carbon nitride family, the graphite-like carbon nitride is expected to be an ideal material to replace carbon materials due to its graphite-like lamellar structure and specific element composition. Due to its unique nanostructure-dependent and p-conjugated systems inherent in aromatic skeletons, the synthesized materials have been widely used in many potential applications such as photocatalysis, oxygen reduction reaction, hydrogen or oxygen evolution reaction, etc. However, its application as a combustion catalyst in AP and propellants has rarely been reported.

Combustion catalyst has a wide range of applications in the field of aerospace solid propellants, which is utilized to adjust the ballistic performance and improve the burning rate. Numerous catalysts have been found to be effective for catalytic propellants. Widely applied are transition metal oxide (TMO), ${ }^{68-77}$ composite metal oxide ${ }^{78}$ ferrocene and its derivatives, ${ }^{79-82}$ carbon materials (such as CNTs and graphene), ${ }^{83}$ MOFs materials, ${ }^{\mathbf{8 4 , 8 5}}$ Continuous research on new and efficient burning rate catalysts, widening the propellant burning rate range and lowering the pressure index has always been a difficult problem for researchers to solve.

Peng et al. found for the first time that $\mathrm{g}-\mathrm{C}_{3} \mathrm{~N}_{4}$ is a neoteric metal-free and environmentally friendly catalyst for AP thermal decomposition. ${ }^{32}$ The HTD temperature was decreased from 454.4 ${ }^{\circ} \mathrm{C}$ to $384.4{ }^{\circ} \mathrm{C}$, and the exothermic heat was increased from $574.2 \mathrm{~J} \mathrm{~g}^{-1}$ to $1362.6 \mathrm{~J} \mathrm{~g}^{-1}$ (Fig. 14). A possible mechanism was illustrated in Fig. 15. g- $\mathrm{C}_{3} \mathrm{~N}_{4}$ is easy to meet the requirement of heat excitation. Under photoexcitation or thermal excitation, the conduction-band electrons $\left(\mathrm{e}^{-}\right)$and valence band holes $\left(\mathrm{h}^{+}\right)$ could be produced on the surface of $\mathrm{g}-\mathrm{C}_{3} \mathrm{~N}_{4}$. Then, the generated electrons $\left(\mathrm{e}^{-}\right)$can react with $\mathrm{HClO}_{4}$ molecules to reduce them to superoxide radical anions ${ }^{\circ} \mathrm{O}_{2}{ }^{-}$. Subsequently, the ${ }^{\circ} \mathrm{O}_{2}{ }^{-}$
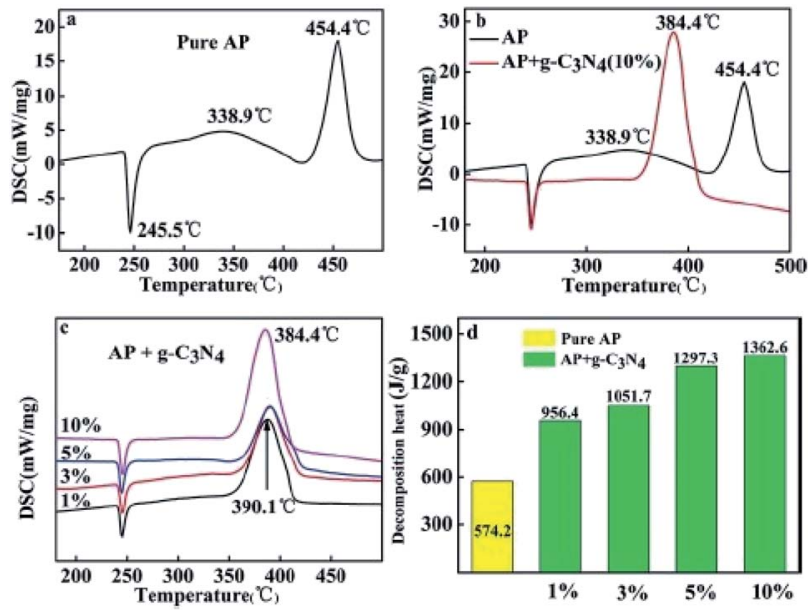

Fig. 14 DSC curves of pure AP (a), AP mixed with $10 \mathrm{wt} \%$ as prepared $\mathrm{g}-\mathrm{C}_{3} \mathrm{~N}_{4}$ at a heating rate of $10^{\circ} \mathrm{C} \mathrm{min}^{-1}$ (b), AP mixed with $\mathrm{g}-\mathrm{C}_{3} \mathrm{~N}_{4}$ ( $1 \mathrm{wt} \%, 3 \mathrm{wt} \%, 5 \mathrm{wt} \%, 10 \mathrm{wt} \%$ ) at a heating rate of $10{ }^{\circ} \mathrm{C} \mathrm{min}^{-1}$ (c), the catalytic effect comparison of no catalyst and $\mathrm{g}-\mathrm{C}_{3} \mathrm{~N}_{4}$ (d). 


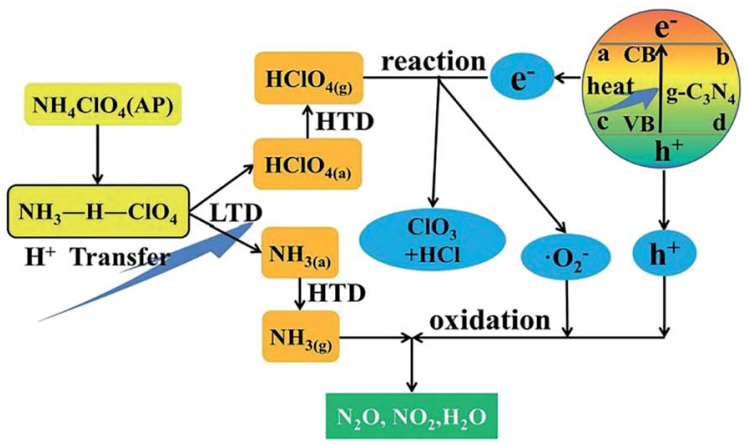

Fig. 15 Schematic of the thermal decomposition process of AP with g- $\mathrm{C}_{3} \mathrm{~N}_{4} \cdot{ }^{32}$

and $\mathrm{h}^{+}$could react with $\mathrm{NH}_{4}{ }^{+}$, promoting the process of proton transfer. The unique surface structure of $\mathrm{g}^{-} \mathrm{C}_{3} \mathrm{~N}_{4}$, composed of triazine with planar amino connections, facilitates the adsorption and diffusion of perchloric acid through Lewis acid-base interactions. Therefore, the Lewis acid-base interaction between $\mathrm{g}-\mathrm{C}_{3} \mathrm{~N}_{4}$ and $\mathrm{HClO}_{4}$ may reduce the activation energy of $\mathrm{AP}$, resulting in the accelerated thermal decomposition of AP.

This material does have a catalytic effect on the decomposition of AP. Nevertheless, bulk g- $\mathrm{C}_{3} \mathrm{~N}_{4}$ usually possesses a faint catalytic effect. Tan and coworkers combined the g- $\mathrm{C}_{3} \mathrm{~N}_{4}$ with $\mathrm{CeO}_{2}$ by utilizing a simple and convenient mixing-calcination technology. ${ }^{33} \mathrm{CeO}_{2}$ itself is an effective combustion catalyst, which can combine with carbon nitride to produce a synergistic effect, resulting in a stronger catalytic effect and the thermal decomposition process of AP with g- $\mathrm{C}_{3} \mathrm{~N}_{4} / \mathrm{CeO}_{2}$ nanocomposites was illustrated in Fig. 16. Specifically, the HTD temperature was decreased from $425.1{ }^{\circ} \mathrm{C}$ to $375.1{ }^{\circ} \mathrm{C}$ (Fig. 17). Peng et al. successfully prepared $\mathrm{SnO}_{2} / \mathrm{g}^{-} \mathrm{C}_{3} \mathrm{~N}_{4}$ hybrids. $\mathrm{SnO}_{2}$, as an excellent semiconductor, possesses a synergistic effect on g$\mathrm{C}_{3} \mathrm{~N}_{4} \cdot{ }^{34}$

Tan et al. synthesized g- $\mathrm{C}_{3} \mathrm{~N}_{4} / \mathrm{CuO}$ nanocomposite through facial precipitation. In addition, they explored the effect of the ratio of copper oxide $(5 \%, 10 \%, 20 \%, 30 \%, 50 \%)$ to carbon nitride on the catalytic effect. ${ }^{35}$ With the increase of copper oxide content, the catalytic effect is getting better. It is because

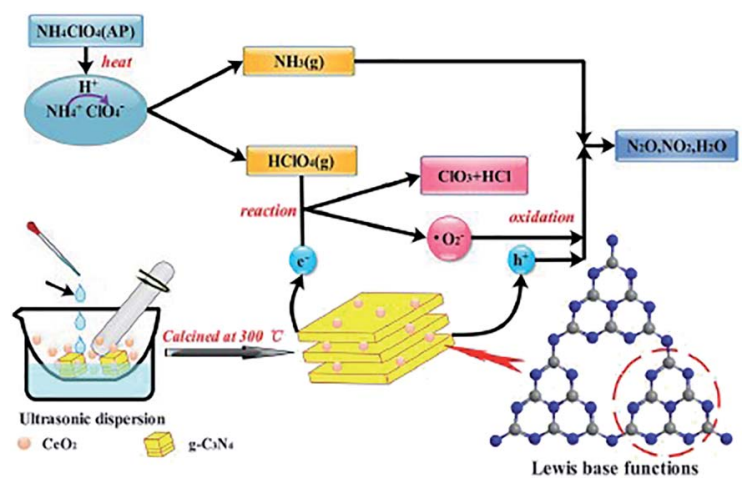

Fig. 16 Schematic illustration of the thermal decomposition process of AP with $\mathrm{g}-\mathrm{C}_{3} \mathrm{~N}_{4} / \mathrm{CeO}_{2}$ nanocomposites. ${ }^{33}$
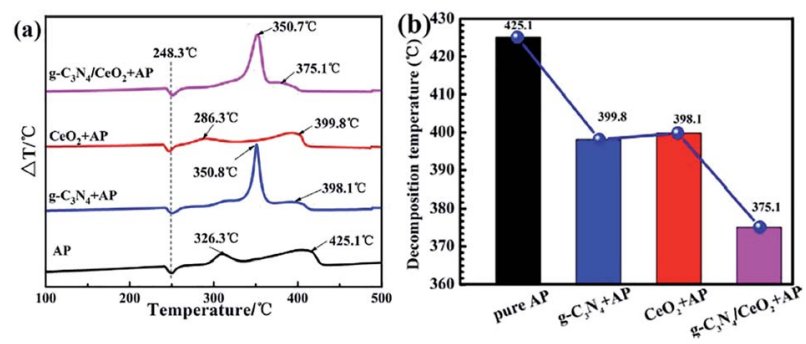

Fig. 17 DTA curves of pure AP (a), AP mixed with g- $\mathrm{C}_{3} \mathrm{~N}_{4}, \mathrm{CeO}_{2}$ and g$\mathrm{C}_{3} \mathrm{~N}_{4} / \mathrm{CeO}_{2}$ nanocomposites (b).


Fig. 18 (a) Differential Thermal Analysis (DTA) curves of ammonium perchlorate (AP) in the absence and presence of a catalyst; (b) histogram of the corresponding high decomposition temperature.
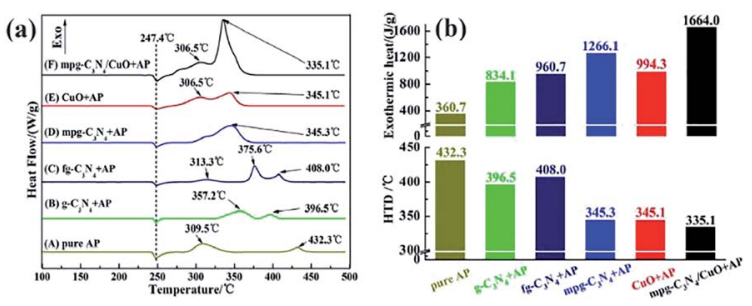

Fig. 19 (a) DSC curves of AP in the absence and presence of catalyst, (b) histogram of the corresponding high decomposition temperature (HTD) and exothermic heat in (a).

copper oxide itself has a stronger catalytic effect than g- $\mathrm{C}_{3} \mathrm{~N}_{4}$. Especially, when $2 \mathrm{wt} \% \mathrm{~g}-\mathrm{C}_{3} \mathrm{~N}_{4} / 20 \% \mathrm{CuO}$ was added as a catalyst, the HTD of AP shows a maxim reduction of $105^{\circ} \mathrm{C}$ (Fig. 18). However, overlarge $\mathrm{CuO}$ content (more than $30 \%$ ) will lead to the agglomeration of $\mathrm{CuO}$ nanosheets, which caused the reduced catalytic effect.

Previous research has demonstrated that high specific surface area facilitates better catalytic performance. Beyond that, higher specific surface area is beneficial to the dispersion of nanoparticles. Thus, plentiful efforts have been made to improve the surface area of $\mathrm{g}-\mathrm{C}_{3} \mathrm{~N}_{4}$. Concretely, Xu et al. introduced silica as a template, increasing the specific surface area from $3.2 \mathrm{~m}^{2} \mathrm{~g}^{-1}$ to $49.8 \mathrm{~m}^{2} \mathrm{~g}^{-1} .{ }^{36}$ Compared with bulk g- $\mathrm{C}_{3} \mathrm{~N}_{4}$, mesoporous $\mathrm{g}-\mathrm{C}_{3} \mathrm{~N}_{4}$ exhibited a promising catalytic effect (Fig. 19), which was assigned to its unique mesoporous structure and large specific surface area. Once combined with $\mathrm{CuO}$, they exhibited better catalytic performance. 

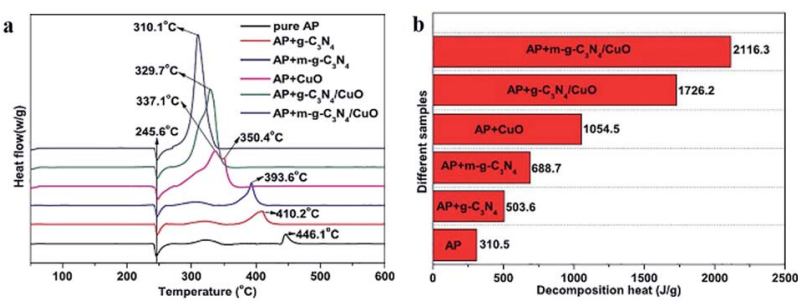

Fig. 20 (a) DSC curves of pure AP, AP + g- $C_{3} N_{4}, A P+m-g-C_{3} N_{4}, A P+$ $\mathrm{CuO}, \mathrm{AP}+\mathrm{g}-\mathrm{C}_{3} \mathrm{~N}_{4} / \mathrm{CuO}$ and $\mathrm{AP}+\mathrm{m}-\mathrm{g}-\mathrm{C}_{3} \mathrm{~N}_{4} / \mathrm{CuO}$ nanocomposites and (b) heat release during the decomposition of $\mathrm{AP}$ with and without catalysts.

A novel microwave assisted method for preparing m-g- $\mathrm{C}_{3} \mathrm{~N}_{4} /$ $\mathrm{CuO}$ with high porosity and specific surface area using melamine as the precursor of $\mathrm{m}-\mathrm{g}-\mathrm{C}_{3} \mathrm{~N}_{4}$ was introduced by Zhang et al. for the first time. ${ }^{37}$ Microwave treated endows the bulk g$\mathrm{C}_{3} \mathrm{~N}_{4}$ with larger specific surface area and porous network structure. The high decomposition temperature (HTD) of AP was reduced by $136^{\circ} \mathrm{C}$ and the heat release reach up to $2116.3 \mathrm{~J}$ $\mathrm{g}^{-1}$ (Fig. 20), which is much higher than pure AP.

\section{Other applications}

The optical properties of $\mathrm{g}-\mathrm{C}_{3} \mathrm{~N}_{4}$ could be demonstrated by ultraviolet/visible absorption and photoluminescence experiments. In fact, g- $\mathrm{C}_{3} \mathrm{~N}_{4}$ exhibits a typical absorption pattern for organic semiconductors, with a strong band gap adsorption at around $420 \mathrm{~nm}$. When the number of layers decreases, the boundary of the valence band and conduction band will shift to the opposite direction, resulting in quantum confinement effect and blue shift of the intrinsic absorption band, which is consistent with the wide and strong photoluminescence phenomenon, indicating that $\mathrm{g}-\mathrm{C}_{3} \mathrm{~N}_{4}$ nanosheet will show stronger light absorption and response when the thickness of the nanosheet decreases. Some structural characteristics of carbon nitride make it a potential electrode material for use in supercapacitors. Bulk nitride has a small specific surface area and poor conductivity. However, after modification or compounding with other materials, its electrochemical performance has been significantly improved. In addition, $\mathrm{g}-\mathrm{C}_{3} \mathrm{~N}_{4}$ also possesses good mechanical and thermal stability.

\subsection{Photocatalyst}

g- $\mathrm{C}_{3} \mathrm{~N}_{4}$ has been widely used in the field of photocatalysis because of its unique energy band structure, which can catalyze aquatic hydrogen, decompose organic pollutants and even bacteria under visible light. g- $\mathrm{C}_{3} \mathrm{~N}_{4}$ nanosheets with superior photocatalytic activity were prepared with the aid of isopropanol by Sun et al. ${ }^{86}$ The catalytic decomposition of water to produce hydrogen at a rate as high as $1501 \mu \mathrm{mol} \mathrm{g}^{-1} \mathrm{~h}^{-1}$ by g$\mathrm{C}_{3} \mathrm{~N}_{4}$ nanosheets, and the catalytic activity did not decrease significantly for a long time. Dong et al. prepared g- $\mathrm{C}_{3} \mathrm{~N}_{4}$ with high surface areas $\left(96.6 \mathrm{~m}^{2} \mathrm{~g}^{-1}\right)$ by directly heating urea in air for the first time. ${ }^{87}$ The large specific surface area, layered

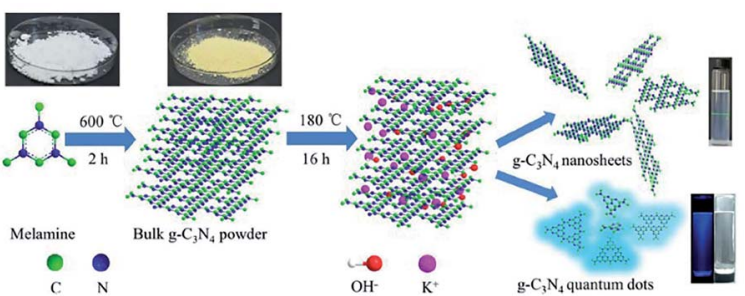

Fig. 21 Schematic illustration of the synthesis of size-controlled g$\mathrm{C}_{3} \mathrm{~N}_{4}$ nanosheets and quantum dots via ethanol-thermal treatment in the presence of $\mathrm{KOH}$.

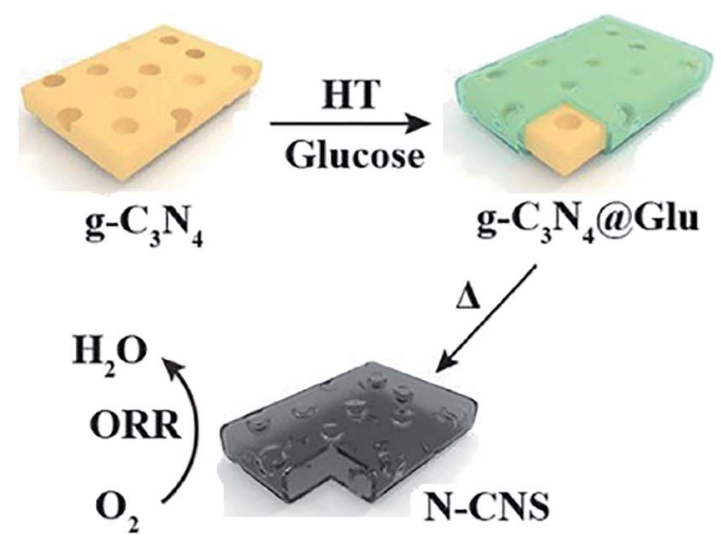

Fig. 22 Schematic illustration of the synthesis of $\mathrm{N}$-doped carbon nanosheets.

structure and appropriate energy band structure contribute to the high efficiency of visible light catalytic activity.

\subsection{Sensor}

Due to the large amount of $-\mathrm{NH}_{2}$ on the surface, g- $\mathrm{C}_{3} \mathrm{~N}_{4}$ has been used as sensors for metal ion monitoring, acid gas detection and biological imaging in recent years. Guo et al. the electrochemical luminescence characteristics of g- $\mathrm{C}_{3} \mathrm{~N}_{4}$ after protonation and exfoliation in detail, and applied it to electroluminescence detection of trace amounts of $\mathrm{Cu}^{2+}$ in solution, expanding the application of $\mathrm{g}_{-}-\mathrm{C}_{3} \mathrm{~N}_{4}$ in electrochemical detection. ${ }^{88}$ Zhan et al. introduced a simple and economical pathway to prepare $\mathrm{g}-\mathrm{C}_{3} \mathrm{~N}_{4}$ quantum dots and $\mathrm{g}-\mathrm{C}_{3} \mathrm{~N}_{4}$ nanosheets (Fig. 21). The materials synthesized by this method had good biocompatibility and were promising candidate materials for biological species in biomedical applications. ${ }^{89}$

\subsection{Nitrogen source}

$\mathrm{Yu}$ et al. synthesized $\mathrm{N}$-doped carbon nanosheets with high areas $\left(1077 \mathrm{~m}^{2} \mathrm{~g}^{-1}\right)$ and high $\mathrm{N}$ contents $(11.6 \%)$ using g- $\mathrm{C}_{3} \mathrm{~N}_{4}$ as both template and nitrogen source (Fig. 22).$^{90}$ This approach described in this study is simple and is expected to lay the foundation for the future development of metal-free electrocatalysts for ORR and other applications. Recently, Wang et al. synthesized a metal-free multilayer porous $\mathrm{N}$-doped carbon 


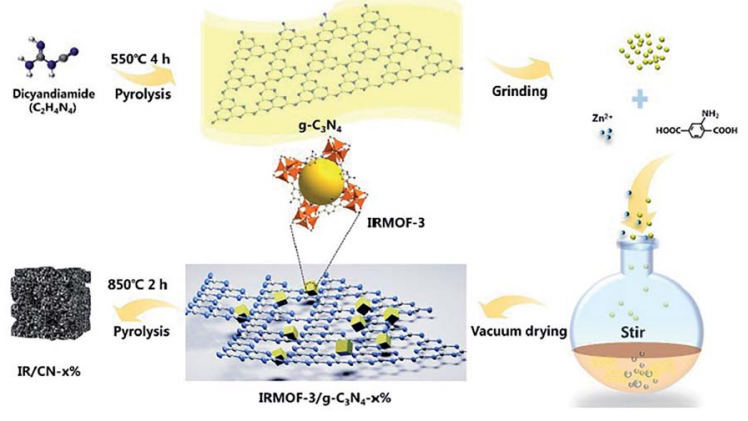

Fig. 23 Schematic of the synthesis process of IR/CN-x\% catalysts.

electrocatalyst in the presence of $\mathrm{g}-\mathrm{C}_{3} \mathrm{~N}_{4}$ as nitrogen source (Fig. 23), which demonstrated excellent ORR performance. ${ }^{91}$

\subsection{Energy storage material}

g- $\mathrm{C}_{3} \mathrm{~N}_{4}$ has great potential in energy storage materials due to its good chemical stability and high specific surface area. From Panigrahi's DFT simulations, g- $\mathrm{C}_{3} \mathrm{~N}_{4}$ sheet had been investigated as $\mathrm{H}_{2}$ storage materials. ${ }^{92}$

\section{Conclusion and perspectives}

In summary, this review comprehensively introduced the structure, properties, preparation, exfoliation of $g-\mathrm{C}_{3} \mathrm{~N}_{4}$ and its application in catalyzing AP. Bulk $\mathrm{g}-\mathrm{C}_{3} \mathrm{~N}_{4}$ could be obtained by method of electrochemical deposition, solvothermal, solid state reaction and thermal decomposition, among of them, thermal decomposition is the most common way to prepare g- $\mathrm{C}_{3} \mathrm{~N}_{4}$. Due to their low specific surface area and high electron recombination rate, multilayer carbon nitride are hardly used in the catalytic field. However, g- $\mathrm{C}_{3} \mathrm{~N}_{4}$ nanosheets have attracted great interest because of their unique electronic structure and excellent chemical stability, as well as their large specific surface area and faster electron-hole separation rate.

Two-dimensional $\mathrm{g}-\mathrm{C}_{3} \mathrm{~N}_{4}$ nanosheets can be obtained via thermal oxidation etching, liquid phase exfoliation, or chemical exfoliation. Generally, nanosheets prepared by thermal oxidation method usually own a larger specific surface area and the operation steps are relatively simple except that the yield is low. Comparably, the method of liquid exfoliation is also simple to operate and easy to control. Nevertheless, one of the disadvantages is time-consuming for its process. In addition, the method of chemical exfoliation shows significantly improved yield and high efficiency but a large amount of strong acid involved during the process might raise strong environmental concerns. Therefore, it is necessary to pursue a low-energy, high-yield and environmentally-friendly method for large-scale preparation of g- $\mathrm{C}_{3} \mathrm{~N}_{4}$ nanosheets.

The applications of $\mathrm{g}^{-} \mathrm{C}_{3} \mathrm{~N}_{4}$ are mainly focused on photocatalytic, electric-catalytic and heterogeneous catalysis but its catalytic effect on AP has rarely been explored. From the very recent literature, $\mathrm{g}-\mathrm{C}_{3} \mathrm{~N}_{4}$ can indeed catalyze the thermal decomposition of AP and increase the exothermic heat effectively. Additionally, simple elements endow the materials with merits such as metal-free and environmentally-friendly.

In spite of the considerable achievements have been made in g- $\mathrm{C}_{3} \mathrm{~N}_{4}$, the investigations of its large-scale synthesis and catalytic applications are still in their infancy and require the joint efforts of scientists around the world.

\section{Conflicts of interest}

The authors declare that they have no known competing financial interests or personal relationships that could have appeared to influence the work reported in this paper.

\section{Notes and references}

1 M. Groenewolt and M. Antonietti, Adv. Mater., 2005, 17, 1789-1792.

2 X. C. Wang, X. F. Chen, A. Thomas, X. Fu and M. Antonietti, Adv. Mater., 2009, 21, 1609-1612.

3 X. J. Bai, L. Wang and R. L. Zong, J. Phys. Chem. C, 2013, 117, 9952-9961.

4 F. Dong, L. W. Wu, Y. J. Sun, M. Fu, Z. Wu and S. C. Lee, J. Mater. Chem., 2011, 21, 15171-15174.

5 P. Wang, Z. J. Guan, Q. Y. Li and J. Yang, J. Mater. Sci., 2017, 53, 774-786.

6 H. J. Yan and H. X. Yang, J. Alloys Compd., 2011, 509, 126129.

7 W. M. Hu, J. P. Wang, G. Q. Luo, B. Luo, C. Wu, W. Wang, Y. Xiao and J. Li, Acta Biochim. Biophys. Sin., 2013, 45, 857866.

8 C. Wang, W. S. Zhu, Y. H. Xu, H. Xu, M. Zhang, Y. Chao, S. Yin, H. Li and J. Wang, Ceram. Int., 2014, 40, 11627-11635.

9 X. F. Chen, J. S. Zhang, X. Z. Fu, M. Antonietti and X. Wang, J. Am. Chem. Soc., 2009, 131, 11658-11659.

10 F. Dong, Z. W. Zhao, T. Xiong, Z. Ni, W. Zhang, Y. Sun and W. Ho, ACS Appl. Mater. Interfaces, 2013, 5, 11392-11401.

11 J. V. Liebig, Ann. Pharm., 1834, 10, 1-47.

12 E. C. Frankili, J. Am. Chem. Soc., 1922, 44, 486-509.

13 D. M. Teter and R. J. Hemley, Science, 1996, 271, 53-55.

14 X. C. Wang, K. Maeda, A. Thomas, K. Takanabe, G. Xin, J. Carlsson, M. Domen and M. Antoniett, Nat. Mater., 2009, 8, 76-80.

15 C. Li, C. B. Cao and J. T. Zhang, Mater. Sci. Eng., B, 2004, 106, 308-312.

16 X. J. Bai, J. Li and C. B. Cao, Mater. Lett., 2011, 65, 1101-1104. 17 C. C. Hu, M. S. Wang and W. Z. Hung, Chem. Eng. Sci., 2017, 167, 1-9.

18 Z. H. Zhang, K. Leinenweber, M. Bauer, L. A. J. Garvie, P. F. McMillan and G. H. Wolf, J. Am. Chem. Soc., 2001, 123, 7788-7796.

19 M. Todd, J. Kouvetakis, T. L. Groy, D. Chandrasekhar, D. J. Smith and P. W. Deal, Chem. Mater., 1995, 7, 1422-1426.

20 A. Thomas, A. Fischer, F. Goettmann, M. Antonietti, J. Müller, R. Schlögl and J. M. Carlsson, J. Mater. Chem., 2008, 18, 4893-4908.

21 G. H. Dong and L. Z. Zhang, J. Mater. Chem., 2012, 22, 11601166. 
22 B. Chai, T. Y. Peng, J. Mao, K. Li and L. Zan, Phys. Chem. Chem. Phys., 2012, 14, 16745-16752.

23 Y. Zheng, Z. S. Zhang and C. H. Li, J. Photochem. Photobiol., A, 2017, 332, 32-44.

24 S. Z. Hu, L. Ma, J. G. You, F. Li, Z. Fan, F. Wang, D. Liu and J. Gui, RSC Adv., 2014, 4, 21657-21663.

25 J. N. Coleman, M. Lotya, A. O'Neill, S. D. Bergin, P. J. King, U. Khan, K. Young, A. Gaucher, S. De, R. J. Smith, L. V. Shvets, S. K. Arora, G. Stanton, H. Y. Kim, K. Lee, G. T. Kim, G. S. Duesberg, H. Toby, J. J. Boland, J. Wang, J. F. Donegan, J. C. Grunlan, G. Moriarty, A. Shmeliov, R. J. Nicholls, J. M. Perkins, E. M. Grieveson, K. Theuwissen, D. W. McComb, P. D. Nellist and V. Nicolosi, Science, 2011, 331, 568-571.

26 M. Naguib, M. Kurtoglu, V. Presser, J. Lu, J. Niu, M. Heon, L. Hultman, Y. Gogotsi and M. W. Barsaum, Adv. Mater., 2011, 23, 4248-4253.

27 K. G. Zhou, N. N. Mao, H. X. Wang, Y. Peng and H. Zhang, Angew. Chem., 2011, 123, 11031-11034.

28 G. H. Chen, D. J. Wu, W. G. Weng and C. Wu, Carbon, 2003, 41, 619-621.

29 I. Krivtsov, E. I. García-López and G. Marcì, Appl. Catal., B, 2017, 204, 430-439.

30 S. S. Zheng, X. R. Li, B. Y. Yan, Q. Hu, Y. Xu, X. Xiao, H. Xue and H. Pang, Adv. Energy Mater., 2017, 7, 1602733.

31 A. Y. Shi, H. H. Li, S. Yin, B. Liu, J. Zhang and Y. Wang, Appl. Catal., B, 2017, 218, 137-146.

32 Q. Li, Y. He and R. F. Peng, RSC Adv., 2015, 5, 24507-24512.

33 L. H. Tan, J. H. Xu, X. J. Zhang, Z. Hang, Y. Jia and S. Wang, Appl. Surf. Sci., 2015, 356, 447-453.

34 Q. Li, Y. He and R. F. Peng, New J. Chem., 2015, 39, 87038707.

35 L. H. Tan, J. H. Xu, S. Y. Li, D. Li, Y. Dai, B. Kou and Y. Chen, Materials, 2017, 10, 1-13.

36 J. H. Xu, S. Y. Li, L. H. Tan and B. Kou, Mater. Res., 2017, 93, 352-360.

37 Y. Zhang, K. D. Li, J. Liao, X. Wei and L. Zhang, Appl. Surf. Sci., 2020, 499, 143875.

38 L. Chen, X. Wang, L. Song, H. H. Song and Y. P. Zhang, Adv. Mater. Chem., 2015, 3, 13-23.

39 E. Kroke, M. Schwarz, E. Horath-Bordon, P. Kroll, B. Noll and A. D. Norman, New J. Chem., 2002, 26, 508-512.

40 B. Zhu, J. Zhang, C. Jiang, B. Cheng and J. Yu, Appl. Catal., B, 2017, 207, 27-34.

41 J. Liu, J. Alloys Compd., 2016, 672, 271-276.

42 W. H. Brito, J. Silva-Araújo and H. Chacham, J. Phys. Chem. C, 2015, 119, 19743-19751.

43 A. Naseri, M. Samadi, A. Pourjavadi, A. Z. Moshfegh and S. Ramakrishna, J. Mater. Chem. A, 2017, 5, 23406-23433.

44 A. Thomas, A. Fischer, F. Goettmann, M. Antonietti, J. O. Müller, R. Schlögl and J. M. Carlsson, J. Mater. Chem., 2008, 18, 4893-4908.

45 Z. L. Zhao, X. L. Wang, Z. Shu, J. Zhou, T. Li, W. Wang and Y. Tan, Appl. Surf. Sci., 2018, 455, 591-598.

46 S. Cao, J. Low, J. Yu and M. Jaroniec, Adv. Mater., 2015, 27, 2150-2176.
47 S. C. Yan, Z. S. Li and Z. G. Zou, Langmuir, 2009, 25, 1039710401.

48 Y. W. Zhang, J. H. Liu, G. Wu and W. Chen, Nanoscale, 2012, 4, 5300-5303.

49 Y. P. Yuan, L. S. Yin, S. W. Cao, L. Gu, G. Xu, P. Du, H. Chai, Y. Liao and C. Xue, Green Chem., 2014, 16, 4663-4668.

50 J. Q. Wen, J. Xie, X. B. Chen and X. Li, Appl. Surf. Sci., 2017, 391, 72-123.

51 H. L. Gao, S. C. Yan, J. J. Wang, Y. Huang, P. Wang, Z. Li and Z. Zou, Phys. Chem. Chem. Phys., 2013, 15, 18077-18084.

52 H. Zhang, L. H. Guo, L. Zhao, B. Wan and Y. Yang, J. Phys. Chem. Lett., 2015, 6, 958-963.

53 P. Niu, L. L. Zhang, G. Liu and H. Cheng, Adv. Funct. Mater., 2012, 22, 4763-4770.

54 Q. Z. Qian, D. S. Kong, S. Z. Zhao, Q. Qian, D. Kong, S. Zhao, G. Li, X. Cheng, N. Wang, T. Li, D. Li, K. Yang and J. Zang, Opt. Laser Technol., 2019, 111, 597-603.

55 S. B. Yang, Y. J. Gong, J. S. Zhang, L. Zhan, L. Ma, Z. Fang, R. Vajtai, X. Wang and P. M. Ajayan, Adv. Mater., 2013, 25, 2452-2456.

56 H. Wang, Y. Su, H. X. Zhao, H. Yu, S. Chen, Y. Zhang and X. Quan, Environ. Sci. Technol., 2014, 48, 11984-11990.

57 H. X. Zhao, H. T. Yu, X. Quan, S. Chen, H. Zhao and H. Wang, RSC Adv., 2014, 4, 624-628.

58 H. Miao, G. Zhang, X. Hu, J. Mu, T. Han, J. Fan, C. Zhu, L. Song, J. Bai and X. Hou, J. Alloys Compd., 2017, 690, 669-676.

59 G. N. Li, L. Li, H. Y. Yuan, H. Wang, H. Zeng and J. Shi, J. Colloid Interface Sci., 2017, 495, 19-26.

60 X. M. Li, X. Sun, L. Zhang, S. Sun and W. Wang, J. Mater. Chem., 2018, 6, 3005-3011.

61 T. Yu, Z. Liu, J. Ma and X. Tan, Trans. Tianjin Univ., 2020, 26, 40-48.

62 X. D. Zhang, X. Xie, H. Wang, J. Zhang, B. Pan and Y. Xie, J. Am. Chem. Soc., 2012, 135, 18-21.

63 L. F. Zhang, F. R. Huang, C. H. Liang, L. Zhou, X. Zhang and Q. Pang, J. Taiwan Inst. Chem. Eng., 2016, 60, 643-650.

64 X. P. Dong and F. X. Cheng, J. Mater. Chem. A, 2015, 3, 2364223652.

65 J. Xu, L. W. Zhang, R. Shi and Y. Zhu, J. Mater. Chem. A, 2013, 1, 14766-14772.

66 J. C. Tong, L. Zhang, F. Li, K. Wang, L. Han and S. Cao, RSC Adv., 2015, 5, 88149-88153.

67 Y. J. Zhang, A. Thomas, M. Antonietti and X. Wang, J. Am. Chem. Soc., 2009, 131, 50-51.

68 Y. H. Hu, S. H. Yang, B. W. Tao, X. Liu, K. Lin, Y. Yang, R. Fan, D. Xia and D. Hao, Vacuum, 2018, 159, 105-111.

69 Y. P. Wang, X. Y. Xia, J. W. Zhu, Y. Li, X. Wang and X. Hu, Combust. Sci. Technol., 2010, 183, 154-162.

70 L. N. Jin, Q. Liu and W. Y. Sun, CrystEngComm, 2012, 14, 7721-7726.

71 L. M. Li, Y. Zhou, Z. Q. Li and C. Pei, Mater. Res. Bull., 2014, 60, 802-807.

72 C. P. Yu, W. C. Zhang, Y. Gao, Y. Chen, K. Ma, J. Ye, R. Shen and Y. Yang, Mater. Res. Bull., 2018, 97, 483-489.

73 S. G. Hosseini, E. Ayoman and A. Kashi, Part. Sci. Technol., 2017, 36, 751-761. 
74 G. Z. Hao, X. Zhou, X. L. Liu, B. Gou, L. Xiao, J. Liu, W. Jiang, F. Zhao and H. Gao, J. Energ. Mater., 2019, 37, 484-495.

75 Y. Yang, X. J. Yu, J. Wang and Y. Wang, J. Nanomater., 2011, 2011, 1-5.

76 R. A. Chandru, S. Patra, C. Oommen, N. Munichandraiah and B. N. Raghunandan, J. Mater. Chem., 2012, 22, 65366538.

77 I. P. S. Kapoor, P. Srivastava and G. Singh, Propellants, Explos., Pyrotech., 2009, 34, 351-356.

78 H. B. Liu, Q. Z. Jiao, Y. Zhao, H. Li, C. Sun, X. Li and H. Wu, Mater. Lett., 2010, 64, 1698-1700.

79 P. Povea, J. L. Arroyo, G. Carreño, Á. Norambuena, P. L. Rios, M. B. Camarada, L. Chavez, J. M. Manriquez and C. MoralesVerdejo, Thermochim. Acta, 2018, 666, 181-189.

80 W. D. Zhou, L. Wang, H. J. Yu and X. Xia, Appl. Organomet. Chem., 2018, 32, 1-9.

81 B. U. Amin, H. Yu, L. Wang, A. Nazir, S. Fahad, F. Haq, S. Mahmood, R. X. Liang, M. A. Uddin and T. F. Lin, J. Organomet. Chem., 2020, 921, 121368.

82 J. L. Arroyo, P. Povea, R. Faúndez, M. B. Camarada, C. CerdaCavieres, G. Abarca, J. M. Manriquez and C. MoralesVerdejo, J. Organomet. Chem., 2020, 905, 121020.
83 J. P. Melo, P. L. Ríos, P. Povea, C. Morales-Verdejo and M. B. Camarada, ACS Omega, 2018, 3, 7278-7287.

84 S. Wang, B. Y. Ye, C. W. An, J. Wang and Q. Li, J. Mater. Sci., 2019, 54, 4928-4941.

85 Y. J. Yang, Y. Bai, F. Q. Zhao, E. Yao, J. Yi, C. Xuan and S. Chen, RSC Adv., 2016, 6, 67308-67314.

86 H. Sun, X. Z. Zhou, H. Z. Zhang and W. X. Tu, Int. J. Hydrogen Energy, 2017, 42, 7930-7937.

87 F. Dong, L. W. Wu, Y. J. Sun, M. Fu, Z. B. Wu and S. C. Lee, J. Mater. Chem., 2011, 21, 15171.

88 X. R. Guo, Y. Wang, F. Y. Wu, Y. N. Ni and S. Kokot, Microchim. Acta, 2016, 183, 773-780.

89 Y. Zhan, Z. M. Liu, Q. Q. Liu, D. Huang, Y. Wei, Y. C. Hu, X. J. Lian and C. F. Hu, New J. Chem., 2017, 41.

90 H. J. Yu, L. Shang, T. Bian, R. Shi, C. I. N. Waterhouse, Y. F. Zhao, C. Zhou, L. Z. Wu, C. H. Tung and T. R. Zhang, Adv. Mater., 2016, 28, 5080-5086.

91 Y. Wang, K. Q. Zhong, Z. Y. Huang, L. Y. Chen, Y. Dai, H. G. Zhang, M. H. Su, J. Yan, S. R. Yang, M. Li, T. Xu and J. F. Tang, J. Power Sources, 2020, 450, 227681.

92 P. Panigrahi, A. Kumar, A. Karton, R. Ahuja and T. Hussain, Int. J. Hydrogen Energy, 2019, 11, 184. 